\title{
Continuous Change Mapping to Understand Wetland Quantity and Quality Evolution and Driving Forces: A Case Study in the Liao River Estuary from 1986 to 2018
}

\author{
Jianwei Peng ${ }^{1,2}$, Shuguang Liu ${ }^{1,2, *}$, Weizhi Lu ${ }^{1,2}$, Maochou Liu ${ }^{1,2}$, Shuailong Feng ${ }^{1,2}$ and Pifu Cong ${ }^{3}$ \\ 1 National Engineering Laboratory for Applied Technology of Forestry \& Ecology in South China, Central \\ South University of Forestry and Technology (CSUFT), Changsha 410004, China; \\ jwpeng1119@gmail.com (J.P.); weizhilu@csuft.edu.cn (W.L.); 20191100151@csuft.edu.cn (M.L.); \\ 20200100032@csuft.edu.cn (S.F.) \\ 2 College of Life Science and Technology, Central South University of Forestry and Technology (CSUFT), \\ Changsha 410004, China \\ 3 National Marine Environmental Monitoring Center, Dalian 116023, China; pfcong@nmemc.org.cn \\ * Correspondence: 120170081@csuft.edu.cn
}

Citation: Peng, J.; Liu, S.; Lu, W.; Liu, M.; Feng, S.; Cong, P. Continuous Change Mapping to Understand Wetland Quantity and Quality Evolution and Driving Forces: A Case Study in the Liao River Estuary from 1986 to 2018. Remote Sens. 2021, 13, 4900. https://doi.org/10.3390/ rs13234900

Academic Editors: Mi Wang, Hanwen Yu, Jianlai Chen and Ying Zhu

Received: 14 October 2021 Accepted: 30 November 2021 Published: 2 December 2021

Publisher's Note: MDPI stays neutral with regard to jurisdictional claims in published maps and institutional affiliations.

Copyright: (c) 2021 by the authors Licensee MDPI, Basel, Switzerland. This article is an open access article distributed under the terms and conditions of the Creative Commons Attribution (CC BY) license (https:// creativecommons.org/licenses/by/ $4.0 /)$.

\begin{abstract}
Coastal wetland ecosystems, one of the most important ecosystems in the world, play an important role in regulating climate, sequestering blue carbon, and maintaining sustainable development of coastal zones. Wetland landscapes are notoriously difficult to map with satellite data, particularly in highly complex, dynamic coastal regions. The Liao River Estuary (LRE) wetland in Liaoning Province, China, has attracted major attention due to its status as Asia's largest coastal wetland, with extensive Phragmites australis (reeds), Suaeda heteroptera (seepweed, red beach), and other natural resources that have been continuously encroached upon by anthropogenic landuse activities. Using the Continuous Change Detection and Classification (CCDC) algorithm and all available Landsat images, we mapped the spatial-temporal changes of LRE coastal wetlands (e.g., seepweed, reed, tidal flats, and shallow marine water) annually from 1986 to 2018 and analyzed the changes and driving forces. Results showed that the total area of coastal wetlands in the LRE shrank by $14.8 \%$ during the study period. The tidal flats were the most seriously affected type, with $45.7 \%$ of its total area lost. One of the main characteristics of wetland change was the concurrent disappearance and emergence of wetlands in different parts of the LRE, creating drastically different mixtures of wetland quality (e.g., wetland age composition) in addition to area change. The reduction and replacement/translocation of coastal wetlands were mainly caused by human activities related to urbanization, tourism, land reclamation, and expansion of aquaculture ponds. Our efforts in mapping annual changes of wetlands provide direct, specific, and spatially explicit information on rates, patterns, and causes of coastal wetland change, both in coverage and quality, so as to contribute to the effective plans and policies for coastal management, preservation, and restoration of coastal ecosystem services.
\end{abstract}

Keywords: coastal wetlands; land cover types; Landsat; land cover conversion; driving forces; wetland persistence

\section{Introduction}

As the ecotone between terrestrial and marine ecosystems, coastal wetlands offer a myriad of ecosystem services and play a key role in maintaining coastal biodiversity and human welfare [1,2]. However, human activities coupled with climate change have led to the degradation and loss of coastal wetlands, thereby devaluing ecosystem services [3]. In China, 58\% of the coastal wetlands $\left(8.01 \times 10^{4} \mathrm{~km}^{2}\right)$ disappeared between 1950 and 2014 [4], which led to changes in coastal landscape, species diversity, soil properties, and wildlife habitat $[5,6]$. 
Understanding the causes, processes, and results of coastal wetland landscape evolution is very important for their protection. In the past few decades, human activities and climate change, as manifested through land reclamation, sea reclamation, and sea level rise, have greatly reduced the area of coastal wetlands, with obvious ecological consequences [7]. The important value and significant loss of coastal wetlands in China have attracted the attention of academia, government agencies, and land resource managers [2]. Many studies have investigated land-use changes in coastal wetlands but have mainly focused on the results and causes of land use changes [1,8]. However, few studies have attempted to map annual land-cover transition processes of coastal wetlands using long-term satellite observations [9]. Knowing when, where, and how the land cover has changed is essential for biodiversity conservation, urban planning, habitat assessment, and tracking of biogeochemical cycles [10].

The monitoring of wetlands has always been challenging because they are highly dynamic over space and time [11,12]. Technical and methodological constraints for monitoring wetlands persist [13], although many researchers have attempted wetland classification through land surveys and satellite remote sensing [14-16]. The most typical method for detecting changes in wetlands has been to compare images from two or more dates. However, the time between images acquired in such analyses is often multiple years, which may miss critical, rapidly changing dynamics in between and impedes the analysis of driving forces $[17,18]$.

Various remote sensing methods for land use and land cover (LULC) change detection based on dense time series have been developed in recent years to take advantage of the open Landsat archive (Wulder et al. 2012), including the Landsat-based detection of Trends in Disturbance and Recover (LandTrendr) [19], the vegetation change tracker (VCT) [20], and the Continuous Change Detection and Classification (CCDC) algorithm [21]. Compared with LandTrendr and VCT, the CCDC algorithm uses all spectral bands in Landsat images to detect many kinds of surface change by fitting multiple surface reflectance models with sines and cosines simultaneously and providing land cover maps for any given time $[22,23]$.

The LRE wetland has the second largest reed swamp in the world, and it is the southern feeding boundary for the wild Grus japonensis (red-crowned crane) and the world's largest breeding site for Larus saundersi (Saunders' Gull) [24]. As a coastal wetland ecosystem with high ecological value, the LRE has been degraded in recent years by artificial (pond culture, reclamation of land) and natural disturbances. We used all available Landsat data from 1986 to 2018 to classify LULC change in the LRE area using the CCDC algorithm. We focused on the changes in coastal wetlands, including the tidal flats, shallow marine water, seepweed, and reeds. We aimed to answer the following questions: 1) How suitable is the CCDC method for detecting changes in coastal wetlands? 2) What are the temporal trends, spatial distributions, and transformation directions of LULC change in coastal wetlands?

\section{Data and Methods}

\subsection{Study Area}

The LRE is located in the north of the Bohai Sea (Figure 1), with a coastline $240 \mathrm{~km}$ long and covering an area of about 3500 square $\mathrm{km}$ [25]. The LRE has a temperate monsoon climate. The average annual precipitation is $612 \mathrm{~mm}$, and $70 \%-80 \%$ of the total precipitation occurs between July and September [26]. The LRE wetland became a national nature reserve in 1998 and a Ramsar site in 2005. The boundaries of national nature reserve are defined by Wetland of International Importance (Ramsar Sites) (https: / /rsis.ramsar.org/ris/1441 (accessed on 25 November 2021)). The study area has a unique red beach (from the color of the saline seepweed), extensive reed wetlands, and spectacular artificial aquaculture ponds (Figure 1). 


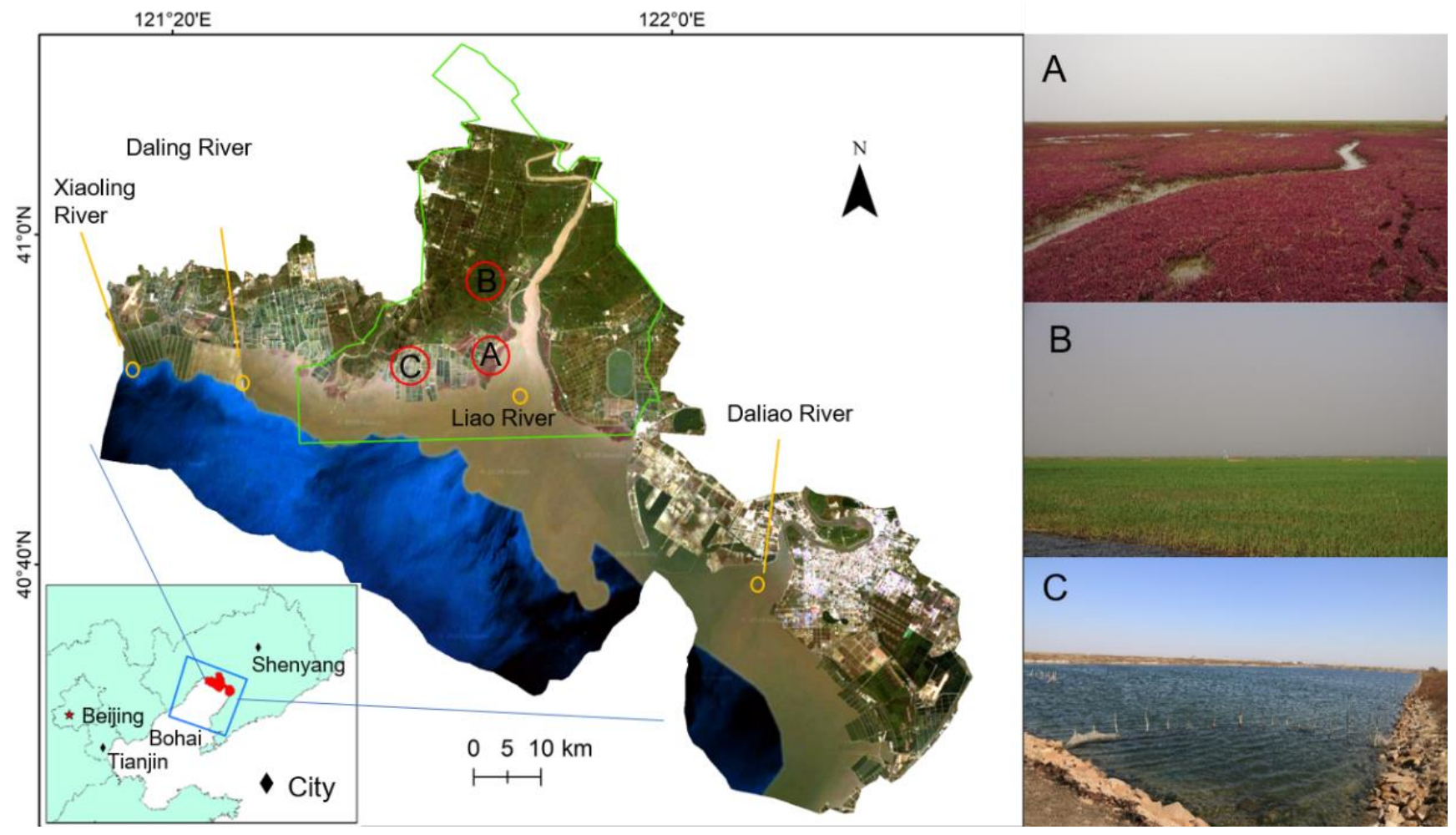

Figure 1. Location of study area in 2018 (data sources: Google satellite imagery). The right panels show (A) seepweed, (B) reeds, and $(\mathbf{C})$ aquaculture ponds. The green line represents the boundaries of national nature reserve.

\subsection{Data Preparation and the CCDC Algorithm}

\subsubsection{Data Acquisition and Preprocessing}

We collected a total of 803 Landsat images for the LRE covering the period 1986-2018 with the Landsat footprint of p120r32 (World Reference System path (p) and row (r)). We used Landsat 5 Thematic Mapper (TM), Landsat 7 Enhanced Thematic Mapper Plus (ETM+), and Landsat 8 Operational Land Imager (OLI) data from United States Geological Survey (USGS) [27], with the percentage of cloud cover below $80 \%$. All data were downloaded from level 2 products of USGS Earth Resources Observation and Science Center's Science Processing Architecture (ESPA), which converted raw digital numbers to six surface reflectance bands (Blue, Green, Red, NIR, SWIR1, and SWIR2) and one thermal band (brightness/surface temperature) values. All images were atmospherically corrected with established correction algorithms [28]. Then, the CFMask algorithm, a method for cloud and cloud shadow detection and removal in Landsat imagery, was used to remove clouds, cloud shadows, and snow for each Landsat image to reduce noise prior to characterizing LULC [29,30]. We downloaded the CCDC version 12.30 from the Global Environmental Remote Sensing (GERS) Laboratory to generate the LULC maps (https:/ / github.com/GERSL/CCDC (accessed on 25 November 2021)). A diagram of the workflow is shown in (Figure 2). 


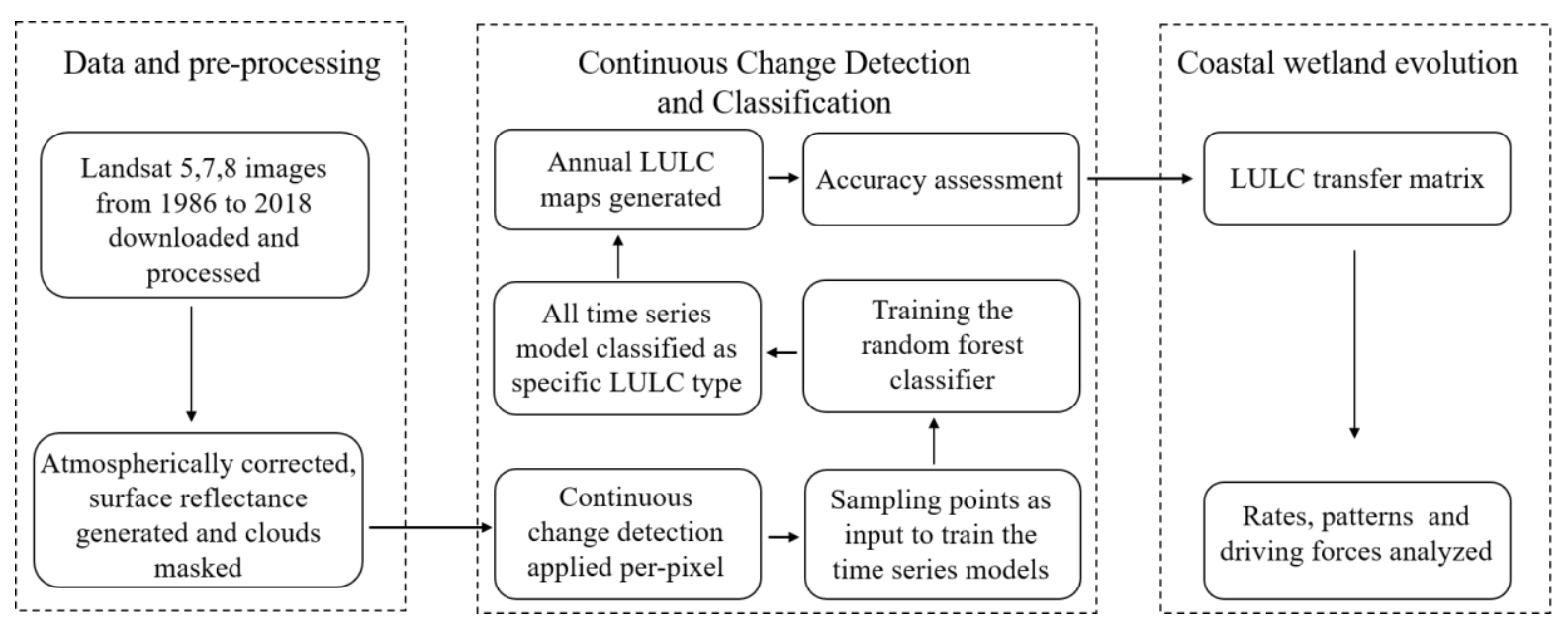

Figure 2. Overall flowchart of this study.

\subsubsection{The CCDC Algorithm and Its Implementation}

We mapped regional LULC changes for annual timesteps using the CCDC algorithm (Zhu and Woodcock 2014). We selected 1 July as the anniversary date due to the images of 1 July having little cloud, no ice or snow cover, and it being the growing season of plants in the study area, which improved the classification accuracy. Specifically, CCDC uses a robust iteratively reweighted least squares (RIRLS) method to iteratively fit observations to the LULC dynamic time-series model that incorporates seasonality, trends (for gradual changes), and breaks (for abrupt changes). The model uses a data-driven threshold approach to identify breaks on the included Landsat bands. In successive dates of images when the spectral signature deviates from the fitted model predictions, CCDC can identify breaks or changes [21]. New observations are added, and their residuals are compared with the RMSE (Root-Mean-Square Error) of the history period. If the error of the new observation is higher than three times the RMSE, it is flagged as a potential change. Once six successive observations are flagged, a change is identified and a new stable model is initialized.

A reference land cover map, based on 2018 Landsat 8 data and field survey data, was developed in a prior study with an overall accuracy of $95 \%$ and used to train the CCDC algorithm. We followed guidance to optimize the selection of training data based on [29], using a total of 20,000 pixels proportionally distributed across eight land cover categories, resulting in 600-8000 pixels per category. Categories included: seepweed, built-up area, forest land, reed field, paddy field, tidal flats, shallow marine water (shallow marine water, river), and aquaculture ponds (aquaculture ponds, reservoirs).

\subsection{Accuracy Assessment}

To assess the accuracy of the synthetic Landsat images, we compared the 2018 classification results against Google Earth images. We selected 9899 pixels proportional to the areal extent of each land cover as the validation dataset. We kept the minimum linear distance between any two pixels at $250 \mathrm{~m}$ (we selected this distance to reduce the potential for auto correlation) [31]. The user accuracy, producer accuracy, overall accuracy, and kappa coefficient of each land cover were calculated [32]. We aimed to achieve a traditional target of an overall accuracy $>85 \%$ [33] to detect the rates of change.

\section{Results}

\subsection{Thematic Classification Characterization}

We used the thematic map output for 2018 (Figure 3) and the 9899 validation points as the basis to assess the accuracy of the Random Forest Classifier (RFC) model. Table 1 shows that the overall accuracy for this map was 0.88 , with an average producer accuracy 
(PA) of 0.79 , an average user accuracy (UA) of 0.85 , and a kappa coefficient of 0.847 . These accuracy levels fit our target and satisfied our study needs. Shallow marine water had the highest PA (0.98) and UA (0.95), followed by reed field ( $P A=0.94, \mathrm{UA}=0.89)$. Forest land had a very small presence in the region, and its relatively lower PA (0.46) and UA (0.71) had limited impact on the overall accuracy estimate.

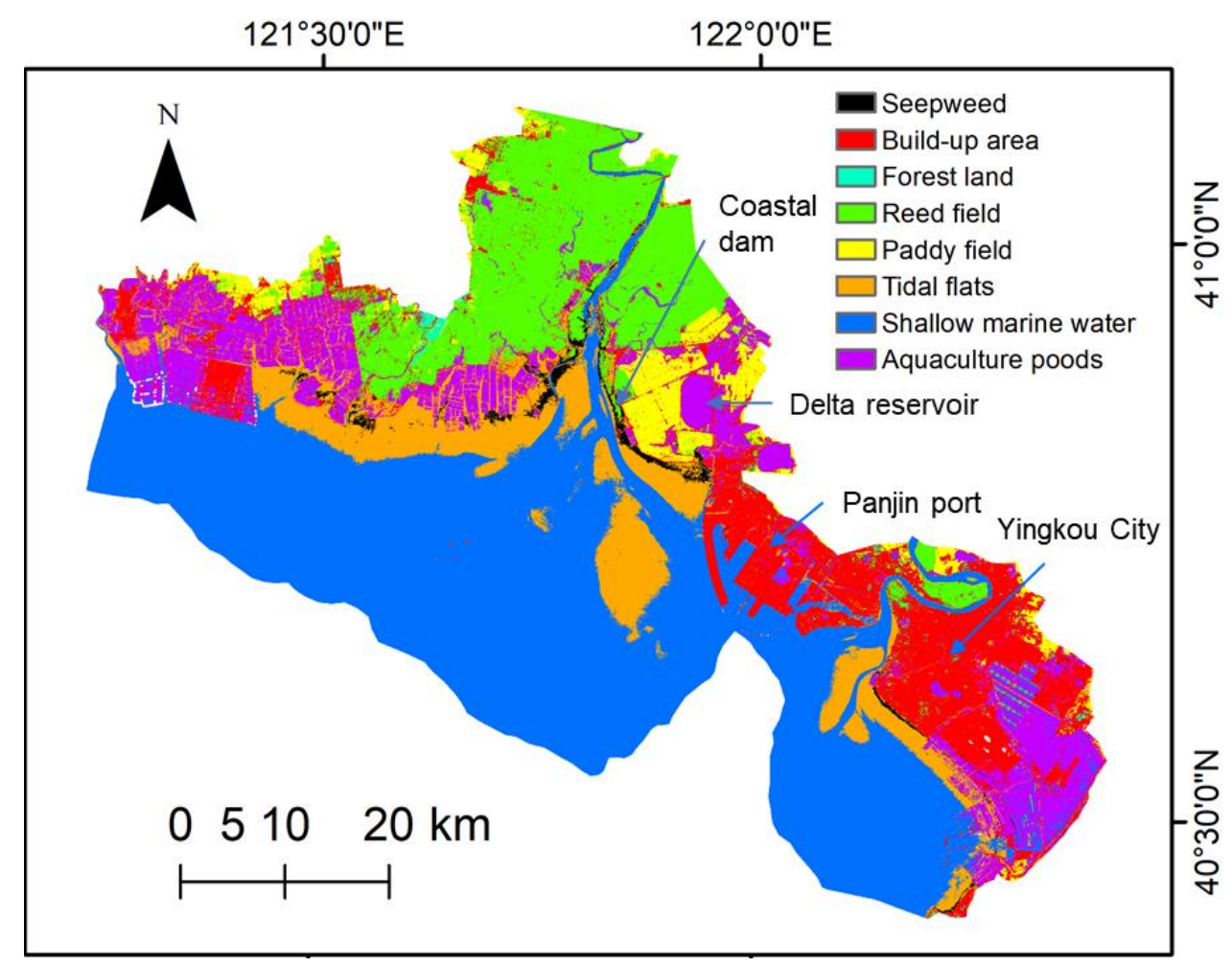

Figure 3. The thematic map output in 2018. The embankment or coastal dam is evident in the 2018 image, along with other new features.

Table 1. The accuracy assessment of classification. SH: seepweed; BA: built-up area; FL: forest land; PA: reed field; PF: paddy field; TF: tidal flats; SMW: shallow marine water; AP: aquaculture ponds.

\begin{tabular}{cccccccccccc}
\hline & SH & BA & FL & PA & PF & TF & SMW & AP & Total \\
& & 91 & 2 & 0 & 0 & 0 & 3 & 1 & 4 & 101 & 0.90 \\
accuracy
\end{tabular}

\subsection{Changes of Coastal Wetlands in the LRE Area}

The area of coastal wetlands in the LRE showed a substantial reduction (Figure 4a) during the study period, decreasing from $2852 \mathrm{~km}^{2}$ to $2431 \mathrm{~km}^{2}$, and its proportional area decreased from $82.7 \%$ to $70.3 \%$. Losses in tidal flats and shallow marine water accounted for most of the decrease in coastal wetlands $(9.4 \%$ and $3.3 \%$ of the total area, respectively) (Figure $4 \mathrm{~b}$ ), while built-up area, aquaculture ponds, and paddy fields increased in extent (7.5\%, $3 \%$, and $1.6 \%$, respectively). 

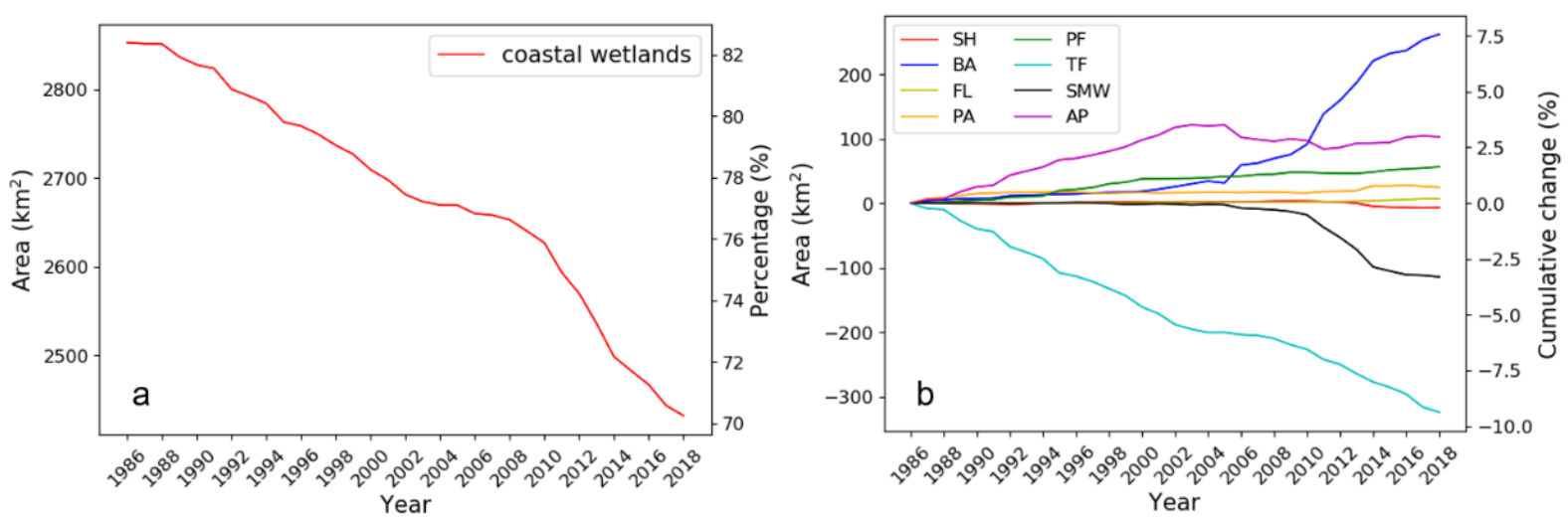

Figure 4. Changes of different land cover types from 1986 to 2018. Coastal wetlands, including seepweed, reed fields, tidal flats, and shallow marine water (a). Area of individual land cover types (b) SH: seepweed; BA: built-up area; FL: forest land; PA: reed field; PF: paddy field; TF: tidal flats; SMW: shallow marine water; AP: aquaculture ponds.

We used a Sankey diagram to represent the direction and proportional area of land cover change (Figure 5). A large area of tidal flats was converted to aquaculture ponds, built-up area, paddy fields, and reeds fields. The aquaculture ponds changed greatly, with abandonment and emergence occurring simultaneously. Shallow marine water was mainly converted into built-up area and aquaculture ponds. The total area of reeds, paddy fields, and forest increased while seepweed reduced.

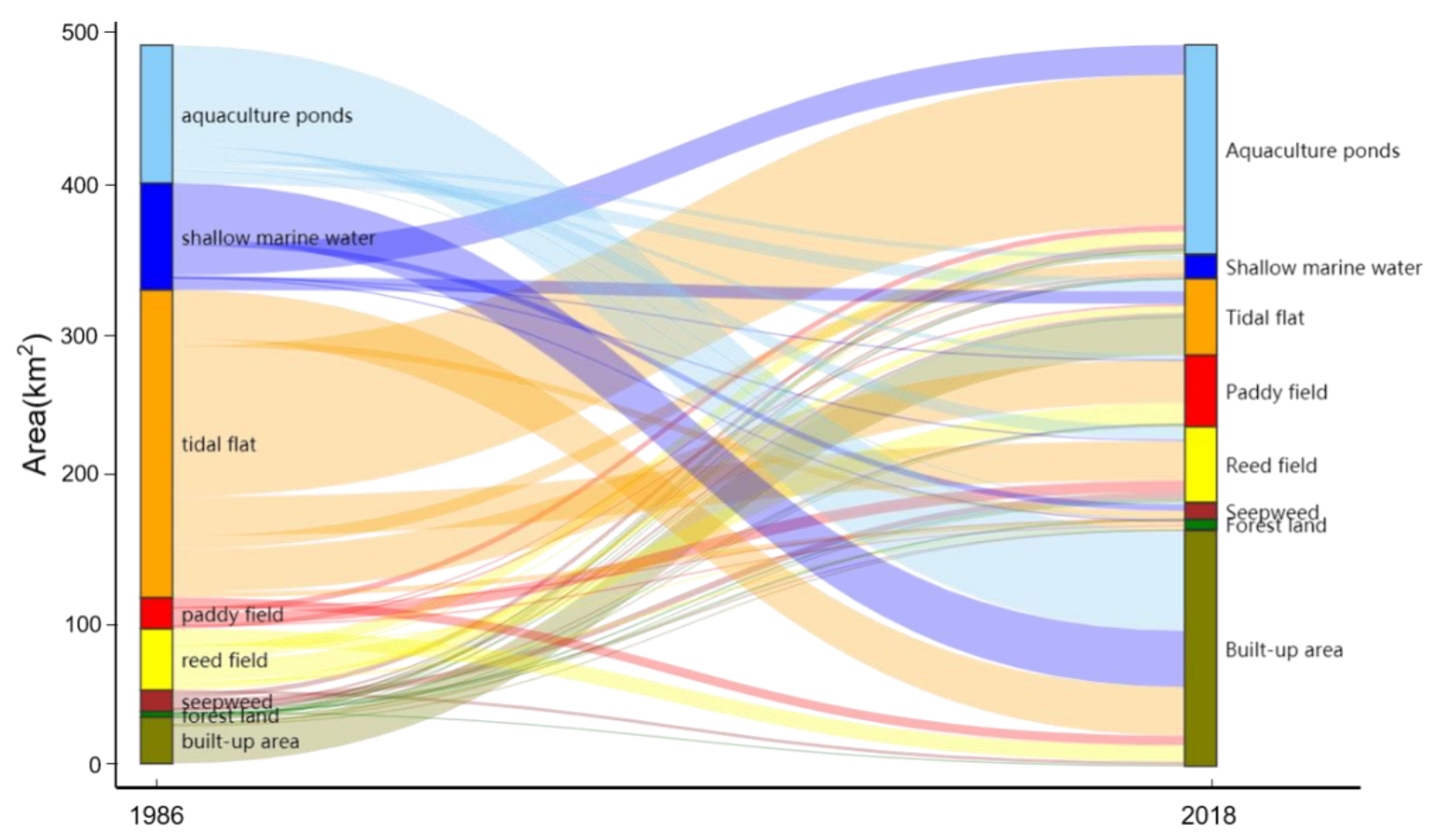

Figure 5. Land cover transitions in the LRE from 1986 to 2018.

\subsection{Spatial-Temporal Dynamics of Coastal Wetlands}

\subsubsection{Vegetated Coastal Wetlands}

The area of seepweed showed a net decrease over the study period (Figure 6A), and was mainly replaced by reeds, which accounted for $32 \%$ of the total area of seepweed lost, followed by aquaculture ponds, built-up area, and shallow marine water (Figure 7A). In contrast, the expansion of seepweed mainly occurred in area of shallow marine water and tidal flats, which accounted for $85 \%$ of the expanded area (Figure $7 \mathrm{~B}$ ). 


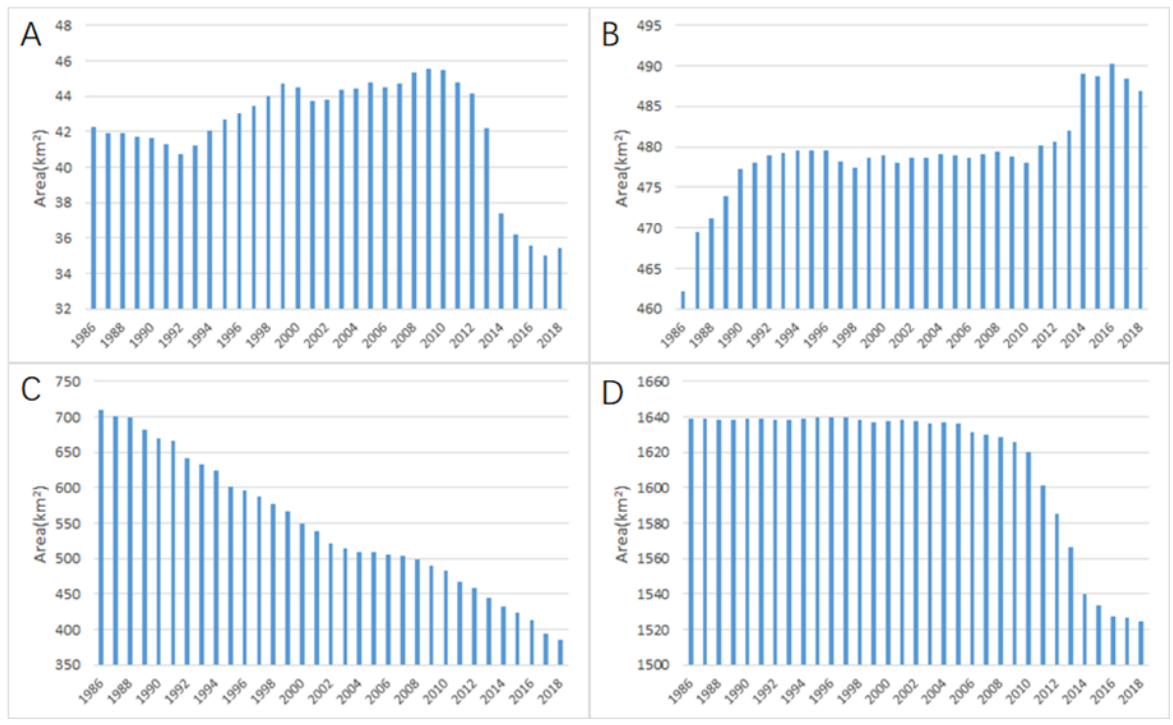

Figure 6. The change of coastal wetlands area in the LRE from 1986 to 2018. (A) seepweed, (B) reeds, (C) tidal flats, (D) shallow marine water.

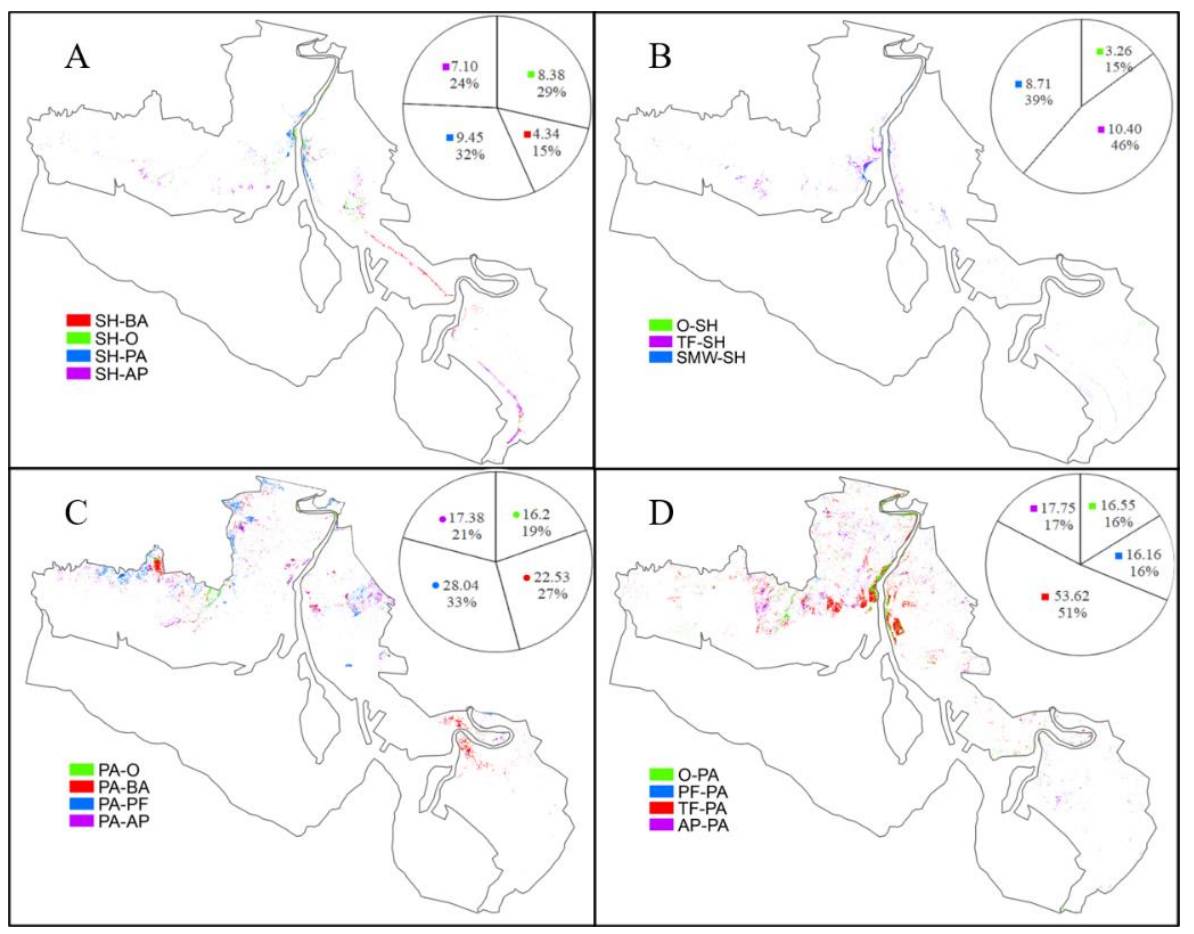

Figure 7. The spatial distribution, quantity $\left(\mathrm{km}^{2}\right)$, and percentage of areal changes in seepweed and reeds. Seepweed converted to other cover types (A); other cover types converted to seepweed (B); reeds converted to other cover types $(\mathbf{C})$; and other cover types converted to reeds (D). SH: seepweed; BA: built-up area; PA: reed field; PF: paddy field; TF: tidal flats; SMW: shallow marine water; AP: aquaculture ponds; O: other covers.

The areal extent of reeds showed an increasing trend over time (Figure 6B). This increase was mainly from tidal flats, accounting for $51 \%$ of the reed increase, followed by aquaculture ponds and agricultural land, accounting for $17 \%$ and $16 \%$, respectively (Figure 7D). The expansion of reeds primarily occurred in the national nature reserve, distributed on both sides of the lower reaches of Liao River. Reeds were mainly lost along the edges of the national nature reserves (Figure 7C), primarily replaced by agricultural 
land and aquaculture ponds, accounting for $33 \%$ and $21 \%$, respectively, of the decrease in the extent of reeds.

\subsubsection{Tidal Flats and Shallow Marine Water}

The extent of tidal flats declined continuously through the study years, resulting in a loss of $324 \mathrm{~km}^{2}(46 \%$ ) (Figure $6 \mathrm{C}$ ). The area transformed from tidal flats to aquaculture ponds was relatively large, $205.96 \mathrm{~km}^{2}$, accounting for $49 \%$ of the loss in tidal flats, followed by built-up area $\left(66.66 \mathrm{~km}^{2}\right)$ and paddy fields $\left(59.19 \mathrm{~km}^{2}\right)$ (Figure $\left.8 \mathrm{~A}\right)$. Paddy field encroachment occurred around the delta reservoir on the east side of the LRE, while the encroachment of built-up area mainly occurred in the port of Panjin.

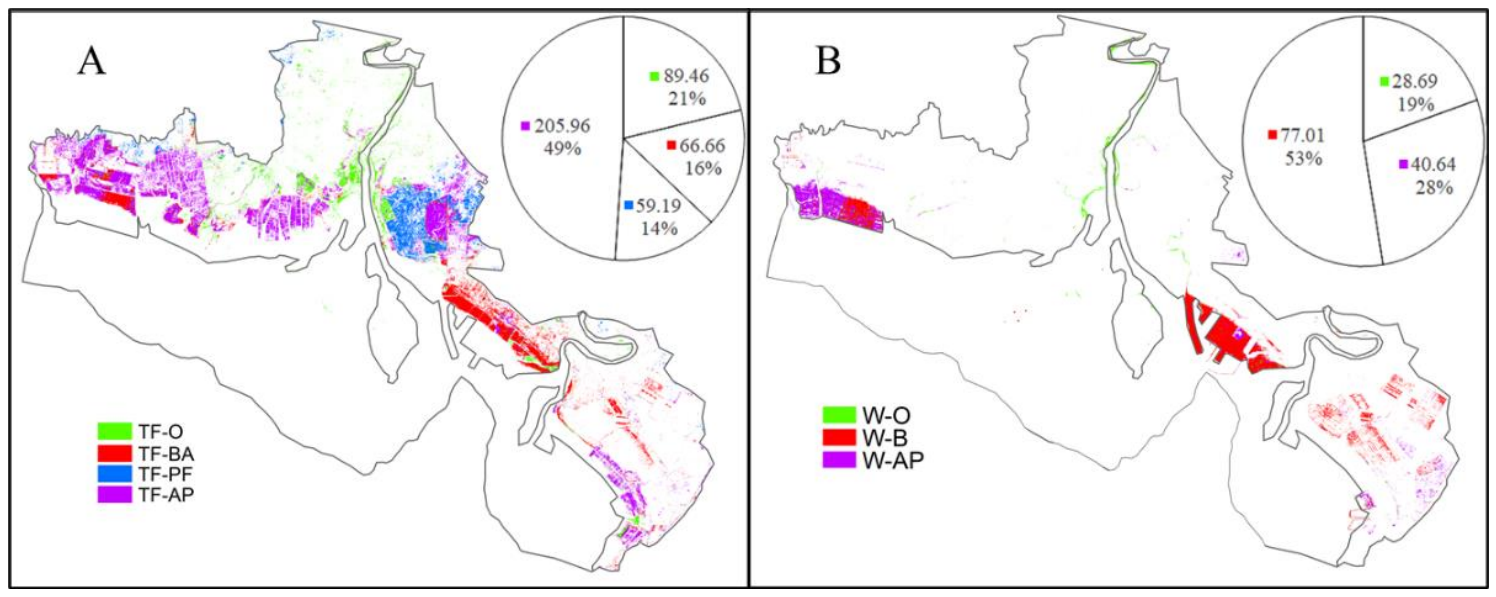

Figure 8. The spatial distribution, quantity $\left(\mathrm{km}^{2}\right)$, and percentage of areal changes in tidal flats and shallow marine water. Tidal flats transformed to other land cover (A) and shallow marine water transformed to other covers (B). BA: built-up area; PA: reed field; PF: paddy field; TF: tidal flats; SMW: shallow marine water; AP: aquaculture ponds; O: other covers.

There was little change in the shallow marine water area before 2005, but then the total area decreased sharply from 2010 to 2014, with a loss of $81 \mathrm{~km}^{2}$ (Figure 6D). The loss was mainly caused by the expansion of built-up land, covering an area of $77 \mathrm{~km}^{2}$, which accounted for $53 \%$ of the loss in extent of shallow marine water (Figure $8 \mathrm{~B}$ ).

\subsection{Existence Time of Vegetated Coastal Wetlands}

Vegetated coastal wetlands (seepweed and reeds) were highly dynamic between 1986 and 2018, as shown by the substantial presence of young-aged wetlands (Figures 9 and 10). The seepweed occupied an area of $42.3 \mathrm{~km}^{2}$ in 1986 and shrank to $35.4 \mathrm{~km}^{2}$ by 2018 (Figure 6A). Seepweed that persisted throughout the study period ( $>32$ years old) accounted for $23.4 \mathrm{~km}^{2}$ and areas of newer seepweed accounted for $12 \mathrm{~km}^{2}$, or more than one-third of the total seepweed area in 2018. The rate of expansion of seepweed escalated over time, as the results indicated increased total area of new seepweed with each successive eight-year interval (Figure 9). Some seepweed expansion was quite temporary, with $9.7 \mathrm{~km}^{2}$ retreating during the study period.

Reeds increased from $462.2 \mathrm{~km}^{2}$ in 1986 to $486.9 \mathrm{~km}^{2}$ by 2018 . The area of reeds that persisted during the entire study period was $422.7 \mathrm{~km}^{2}$ and the area of the newly expanded reeds was $64.2 \mathrm{~km}^{2}$, or $13.9 \%$ of the area in 1986 (Figure 10). The newly emerged reeds lost again during the study period were $31.2 \mathrm{~km}^{2}$. A notable area of reeds, $31.2 \mathrm{~km}^{2}$, represented a temporary expansion that receded again before the end of the study period. 


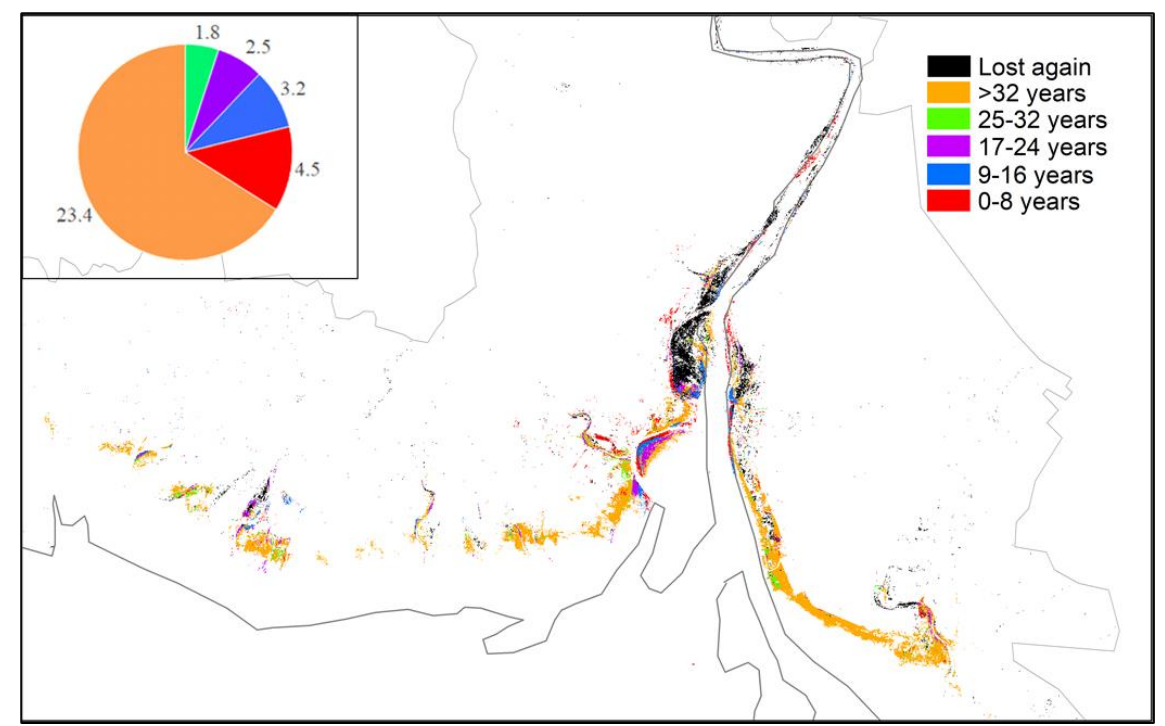

Figure 9. The spatial distribution and quantity of seepweed over time. The black color represents area where seepweed subsequently disappeared after expansion. The pie chart inset shows the area of seepweed in $\mathrm{km}^{2}$ that emerged over time and/or was resident at the beginning of our study years.

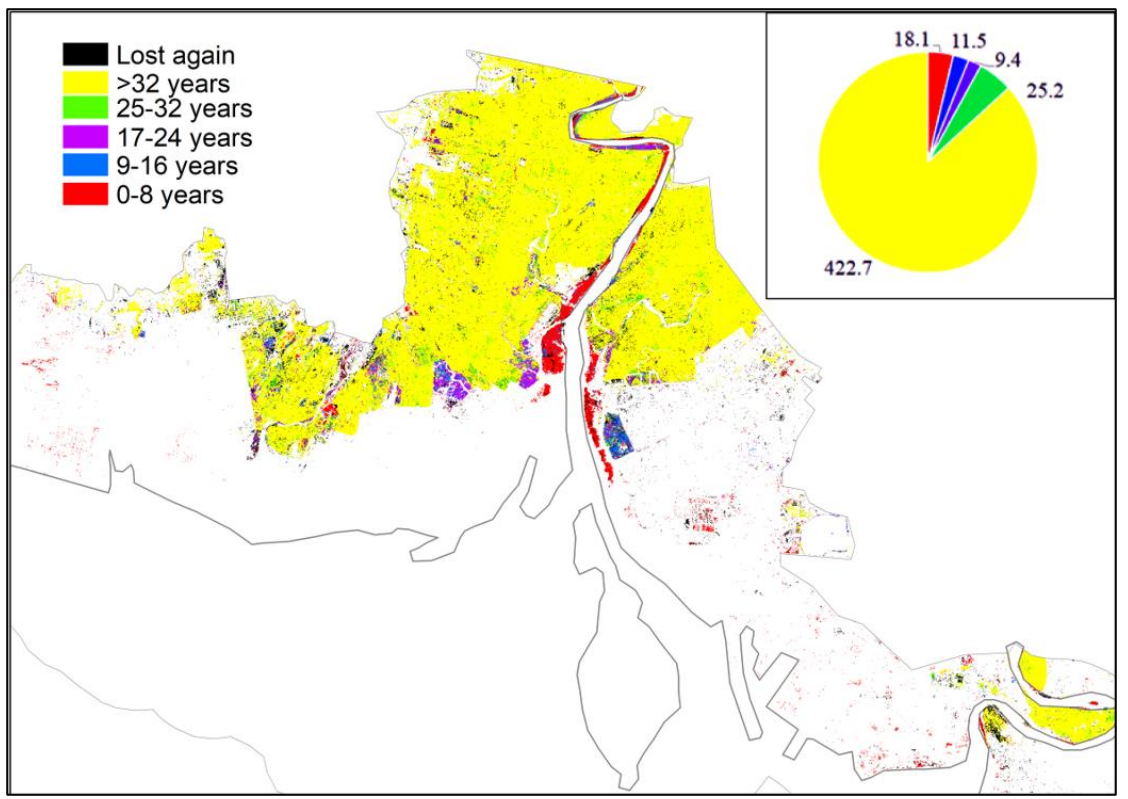

Figure 10. The spatial distribution and persistence time of reeds. The black color represents areas where reeds subsequently disappeared after expansion. The pie chart inset shows the area of reeds in $\mathrm{km}^{2}$ that emerged over time and/or was resident at the beginning of our study years.

\section{Discussion}

\subsection{Driving Forces of Coastal Wetland Changes}

\subsubsection{Seepweed}

The area of seepweed showed an overall downward trend. The construction of embankments and Delta Reservoir have a great influence on the seepweed. For the former, large amounts of silt and nutrients were deposited on the outside of the tidal flats after building an embankment in 1990 in Panjin [34]. Consequently, the soil salinity and nutrients in the peripheral area of the embankment promoted the establishment of seepweed vegetation communities in the wetlands outside the bank dike (Figure 3). The water environment in the inner part of the levee gradually changed from saltwater to freshwater, and some wetlands were converted to paddy fields, contributing to loss of 
seepweed. In addition, recession of seepweed was also associated with the Delta Reservoir (Figure 3), which was built in 1998. The changes in land use from farmland development and reservoir construction were concentrated in the wetlands on the east bank of the LRE [35]. After the completion of the reservoir, the freshwater flowing to the sea from upstream decreased, which altered the soil salt content and material and energy exchange in the habitat of the seepweed.

Aquaculture ponds and built-up area also played major roles in the shrinking of the seepweed. In recent years, with the increasing economic benefits of freshwater fish, crab, and shrimp aquaculture, the aquaculture industry has developed rapidly. Aquaculture on tidal flats directly encroached on the seepweed space by land reclamation; water pollution associated with aquaculture industry had a great impact on seepweed growth as well. Physical replacement of the seepweed by buildings was mainly distributed in Panjin Port. The seepweed grew in long strips on the tidal flats before 1995, which has been altered by the construction of Panjin Port. In addition, sediment elevation has a great influence on seed germination of seepweed [36]. The seeds buried at shallow depths generally have higher rates of germination and emergence, and could only germinate and emerge with sediment burial depth $<5 \mathrm{~cm}$ [36]. Depth of seed burial can influence morphological traits of the plants, and excessive burial may even prevent seedlings from emerging above the sediment surface due to lack of oxygen or light and insufficient temperature for germination or growth.

\subsubsection{Reeds}

The area of the reeds increased over time, though increases and decreases occurred in different places at the same time (Figure 7C,D). The decline in reeds occurred mainly at the edges of the national nature reserve, affected by human activities including land reclamation, oil production, and tourism. Expansion of reeds was mainly in the nature reserve, benefiting from the legal support and government policies associated with environmental governance and protection. The Ramsar Wetland, established in 2005, brought attention to the reeds in the reserve, and a series of conservation measures have resulted in an increase in the area of reeds.

The declining trend of reeds can be attributed to the rapid population growth in the LRE area, which has brought large-scale development of farmland and oilfield exploitation since the 1980s [37]. Farmland reclamation not only encroached on a large number of reed fields, but also led to shortages in freshwater resources. The exploitation of the Liao River oilfield has destroyed the drainage and irrigation system of reed marsh wetlands by constructing wells, roads, and other production and living facilities, resulting in secondary salinization and rapid degradation of the reeds. Tourism has also brought a series of problems to reeds in the form of unreasonable tourism infrastructure construction, and the establishment of some routes and tourist attractions has an impact on the ecological environment [38].

\subsubsection{Tidal Flats and Shallow Marine Water}

Tidal flats underwent the largest, most consistent loss in area in the LRE because of human activities associated with the expansion of aquaculture ponds, building and infrastructure construction, and paddy fields (Figure 8A). The continuous decline of tidal flats was directly related to the continuous expansion of built-up area and aquaculture ponds. LRE area has a long coastline and abundant natural resources. Many farmers developed tidal flats, and collectively and personally occupied wetland resources at will due to the lack of policy constraints in the 1980s, resulting in resource waste and environmental deterioration. As a result of the establishment of the embankment, the marine water in the delta plain transitioned to freshwater, where a large number of tidal flats had been reclaimed into paddy fields (Figure $8 \mathrm{~A}$ ).

The area of shallow marine water declined rapidly after 2010, mainly due to the construction of Panjin Port and the relocation of the new government in Yingkou city. 
The Panjin Port, completed in 2000, and the wharf, completed in 2010, covering an area of 230,000 $\mathrm{m}^{2}$, replaced the tidal flats in the west side of the LRE. Modified shorelines, presence of ship berths, and reclaimed land from the sea altered the nature of the tidal flats and shallow marine water permanently. To the east of Daliao River Estuary lies Yingkou City, which was built up from wetlands with tidal flats and depressions. Yingkou moved the new municipal government building here in 2015 for its superior geographic location. Relocating the new municipal government led to a shift in the center of operations and commerce in Yingkou. Prior to this, the area was made up of aquaculture ponds, tidal flats and water catchment, but the construction of the new government facilities led to a surge in built-land starting from 2006, occupying a large number of aquaculture ponds and tidal flats.

\subsection{Planning and Conservation}

How to balance the protection of natural resources while supporting the economic development of coastal wetland resources is one of the most critical problems of the LRE. Because the loss of reeds tends to occur near the edges of national nature reserves, the government should consider defining buffer zones around the protected areas [39,40]. At present, the transition zones at national nature reserves are narrow, which may be insufficient to protect the wetlands in the nature reserves from human activities external to the reserves. Wide buffer zones with grasses or other vegetation could be established around protected areas.

The expansion of the Yingkou City has encroached on wetlands, aquaculture ponds and beaches, leading to a series of coastal issues. At present, there is a long strip of seepweed in the coastal area of Yingkou City that is very close to urban land. If the urban area continues to expand and wetlands are not protected, the seepweed in this area will likely disappear. If the government has interest in protecting coastal wetlands, our results indicate that proactive efforts will be needed to stop further loss of wetland habitats and functions in the face of further economic development in and around the LRE.

The results showed that for vegetated coastal wetlands, seepweed and reeds showed cyclical change. When they are encroached by other land covers, they can be restored by natural factors or human intervention, or they can also be bred in other places. However, for tidal flats and shallow marine water, their changes are often unidirectional, and it is difficult for them to recover once they are destroyed. Therefore, the government should not only maintain the vegetated coastal wetlands, but also formulate stricter plans on the protection of tidal flats and shallow marine water to reduce the loss of area.

\subsection{Advantages and Limitations}

The Landsat archive provides long-term coverage of the Earth dating back to the 1970s. A single Landsat satellite passes over the same location every 16 days; however, there often have been two Landsat satellites in orbit simultaneously, with offset overpass schedules that provide 8-day revisits [21,41]. The combination of dense time series from Landsat and the CCDC algorithm seemingly performed well in mapping the continuous changes of LRE coastal wetlands. However, we made an assumption that the level of accuracy we measured for the 2018 map was representative and consistent across all the years of our study, an assumption we acknowledge would be difficult to test. Wetlands are known to pose challenges for remote classification, as we stated in the introduction. They are typically difficult to map well because they are very dynamic. Accordingly, their spectral characteristics can change with high temporal frequency in concert with changes in water inundation and fluctuations in vegetation growth [42]. Another caveat is that rates of change reported that were smaller than the error rates measured for a given cover type might not actually represent change. For example, with a user's accuracy of 0.89 and a producer's accuracy of 0.94 for reed field, we cannot be certain that the smaller rates of change that occurred in the intervals prior to 2014 were not due to mapping error (Figure 6B). However, we have a more convincing case for the credibility of small rates of 
change when they can show a consistent or a long-term trend, such as for tidal flats with graph C in Figure 6.

Our work demonstrates how a continuous monitoring approach can provide insights into wetland dynamics that, before now, have been difficult to acquire for sizeable geographic extents. Studying the dynamics in a landscape as complex as the LRE was undoubtedly challenging, and the results show the types of information needed for effective management of wetland resources can be provided through this approach. Compared with previous studies [12,13], our study showed more detailed transformation processes of coastal wetlands, including the timing and locations of change, and how the wetlands were replaced. As a result, we demonstrated that losses and gains in vegetated coastal wetlands occurred simultaneously. Most of the previous work has focused on the degradation and encroachment of coastal wetlands $[34,43]$. However, we found that the vegetated coastal wetlands expanded in some places.

We have shown that continuous long-term monitoring of coastal wetland changes can provide information on the persistence of wetland communities, an important measure of wetland quality. For vegetated coastal wetlands, community persistence can be related to the richness of biodiversity, soil organic matter, and ecosystem functions. Following disturbance, restored wetlands take time to recover the qualities that provide suitable habitats for wildlife. For example, surveys of coastal mangroves showed that newly restored mangroves had higher sand content, lower soil organic matter, lower total carbon, and lower total nitrogen than the original mangroves [44]. Some studies have shown that it takes about three to four years to create wetlands where birds can breed, but longer to reach a more natural state $[45,46]$. Wetland soil properties, such as soil organic matter, total organic carbon, and total nitrogen, generally increased with increased age of wetland vegetation, which also influenced water quality $[47,48]$. The ability to spatially track the persistence of coastal wetlands provides valuable information on the timing and locations of change, the types of transformations associated with the wetlands, and general trends in land cover change needed by resources managers.

\section{Conclusions}

In this study, we used the CCDC algorithm to characterize continuous land cover change information with all available Landsat data, and explored the evolution of processes and driving forces of land cover change in the LRE area. This study showed how a continuous monitoring approach can provide the detailed information needed by managers and planners for a highly dynamic coastal landscape.

The results revealed that coastal wetlands (i.e., tidal flats, shallow marine water, reed field and seepweed) experienced drastic changes in the LRE area, with decreases in wetland area of $421 \mathrm{~km}^{2}(12.4 \%)$ between 1986 and 2018. Coastal wetlands were mainly converted from tidal flats and shallow marine water to built-up area and aquaculture ponds, evidence that the reduction in coastal wetlands in the LRE was mainly caused by human activities. For vegetated coastal wetlands, the total area of seepweed decreased by $7 \mathrm{~km}^{2}(16.32 \%)$ over the study years while total area of reeds increased by $24 \mathrm{~km}^{2}$ $(5.34 \%)$, driven by human activities and natural causes (sedimentation). In addition, we mapped their persistence, which is important for indicating the evolution of wetland quality as it relates to biodiversity and carbon sequestration capacity in the region. Such detailed information on the rates, patterns, and causes of the evolution of coastal wetlands is critical for regional planners and resources managers interested in wetland protection and sustainable development of ecosystem services.

Author Contributions: S.L. designed the research; S.L. and J.P. performed research; and J.P., S.L., W.L., M.L., S.F. and P.C. contributed to the writing of the paper. All authors have read and agreed to the published version of the manuscript.

Funding: This work was supported by research grants from the National Natural Science Foundation of China (41971152 and U20A2089) and Hunan Innovative Talent Program (2019RS1062) to SL. We 
also gratefully acknowledge financial support from Natural Science Foundation of Hunan Province (2021JJ20012), Research Foundation of the Bureau of Education in Hunan Province (20B618) and Start-up Scientific Research Foundation for the Introduction of Talents in Central South University of Forestry Science and Technology (2019YJ018) to W. Lu.

Data Availability Statement: Not available.

Acknowledgments: We would like to thank Zhe Zhu for sharing his CCDC codes.

Conflicts of Interest: The authors declare no conflict of interest.

\section{References}

1. Jiang, T.-T.; Pan, J.-F.; Pu, X.-M.; Wang, B.; Pan, J.-J. Current status of coastal wetlands in China: Degradation, restoration, and future management. Estuar. Coast. Shelf Sci. 2015, 164, 265-275. [CrossRef]

2. Mao, D.; Wang, Z.; Du, B.; Li, L.; Tian, Y.; Jia, M.; Zeng, Y.; Song, K.; Jiang, M.; Wang, Y. National wetland mapping in China: A new product resulting from object-based and hierarchical classification of Landsat 8 OLI images. ISPRS J. Photogramm. Remote Sens. 2020, 164, 11-25. [CrossRef]

3. Ewers Lewis, C.J.; Baldock, J.A.; Hawke, B.; Gadd, P.S.; Zawadzki, A.; Heijnis, H.; Jacobsen, G.E.; Rogers, K.; Macreadie, P.I. Impacts of land reclamation on tidal marsh 'blue carbon' stocks. Sci. Total Environ. 2019, 672, 427-437. [CrossRef]

4. Sun, Z.; Sun, W.; Tong, C.; Zeng, C.; Yu, X.; Mou, X. China's coastal wetlands: Conservation history, implementation efforts, existing issues and strategies for future improvement. Environ. Int. 2015, 79, 25-41. [CrossRef]

5. Yang, H.; Ma, M.; Thompson, J.R.; Flower, R.J. Protect coastal wetlands in China to save endangered migratory birds. Proc. Natl. Acad. Sci. USA 2017, 114, 5491-5492. [CrossRef]

6. Luisa Martínez, M.; Mendoza-González, G.; Silva-Casarín, R.; Mendoza-Baldwin, E. Land use changes and sea level rise may induce a "coastal squeeze" on the coasts of Veracruz, Mexico. Glob. Environ. Chang. 2014, 29, 180-188. [CrossRef]

7. Lin, Q.; Yu, S. Losses of natural coastal wetlands by land conversion and ecological degradation in the urbanizing Chinese coast. Sci. Rep. 2018, 8, 15046-15056. [CrossRef]

8. Chen, L.; Ren, C.; Zhang, B.; Li, L.; Wang, Z.; Song, K. Spatiotemporal Dynamics of Coastal Wetlands and Reclamation in the Yangtze Estuary During Past 50 Years (1960s-2015). Chin. Geogr. Sci. 2018, 28, 386-399. [CrossRef]

9. Zhao, Q.; Bai, J.; Huang, L.; Gu, B.; Lu, Q.; Gao, Z. A review of methodologies and success indicators for coastal wetland restoration. Ecol. Indic. 2016, 60, 442-452. [CrossRef]

10. Meng, G.; Jing, L.; Chunlei, S.; Jiawei, X.; Li, W. A Review of Wetland Remote Sensing. Sensors 2017, 17, 777. [CrossRef]

11. Qureshi, S.; Alavipanah, S.K.; Konyushkova, M.; Mijani, N.; Fathololomi, S.; Firozjaei, M.K.; Homaee, M.; Hamzeh, S.; Kakroodi, A.A. A Remotely Sensed Assessment of Surface Ecological Change over the Gomishan Wetland, Iran. Remote Sens. 2020, 12, 2989. [CrossRef]

12. Wang, X.; Gao, X.; Zhang, Y.; Fei, X.; Chen, Z.; Wang, J.; Zhang, Y.; Lu, X.; Zhao, H. Land-Cover Classification of Coastal Wetlands Using the RF Algorithm for Worldview-2 and Landsat 8 Images. Remote Sens. 2019, 11, 1927. [CrossRef]

13. Jin, H.; Huang, C.; Lang, M.W.; Yeo, I.-Y.; Stehman, S.V. Monitoring of wetland inundation dynamics in the Delmarva Peninsula using Landsat time-series imagery from 1985 to 2011. Remote Sens. Environ. 2017, 190, 26-41. [CrossRef]

14. Di Vittorio, C.A.; Georgakakos, A.P. Land cover classification and wetland inundation mapping using MODIS. Remote Sens. Environ. 2018, 204, 1-17. [CrossRef]

15. Mahdianpari, M.; Salehi, B.; Mohammadimanesh, F.; Brisco, B.; Mahdavi, S.; Amani, M.; Granger, J.E. Fisher Linear Discriminant Analysis of coherency matrix for wetland classification using PolSAR imagery. Remote Sens. Environ. 2018, 206, 300-317. [CrossRef]

16. Chen, S.; Ma, A.; Li, Z. Landscape Pattern Changes and Its Driving Mechanism of the Wetland in Liaohe. Chin. J. Eco-Agric. 2011, $19,468-476$.

17. Yang, T.; Guan, X.; Qian, Y.; Xing, W.; Wu, H. Efficiency Evaluation of Urban Road Transport and Land Use in Hunan Province of China Based on Hybrid Data Envelopment Analysis (DEA) Models. Sustainability 2019, 11, 3826. [CrossRef]

18. Wu, W.; Zhao, S.; Zhu, C.; Jiang, J. A comparative study of urban expansion in Beijing, Tianjin and Shijiazhuang over the past three decades. Landsc. Urban Plan. 2015, 134, 93-106. [CrossRef]

19. Kennedy, R.E.; Yang, Z.; Cohen, W.B. Detecting trends in forest disturbance and recovery using yearly Landsat time series: 1. LandTrendr-Temporal segmentation algorithms. Remote Sens. Environ. 2010, 114, 2897-2910. [CrossRef]

20. Huang, C.; Goward, S.N.; Masek, J.G.; Thomas, N.; Zhu, Z.; Vogelmann, J.E. An automated approach for reconstructing recent forest disturbance history using dense Landsat time series stacks. Remote Sens. Environ. 2010, 114, 183-198. [CrossRef]

21. Zhu, Z.; Woodcock, C.E. Continuous change detection and classification of land cover using all available Landsat data. Remote Sens. Environ. 2014, 144, 152-171. [CrossRef]

22. Zhu, Z.; Zhou, Y.; Seto, K.C.; Stokes, E.C.; Deng, C.; Pickett, S.T.A.; Taubenböck, H. Understanding an urbanizing planet: Strategic directions for remote sensing. Remote Sens. Environ. 2019, 228, 164-182. [CrossRef]

23. Awty-Carroll, K.; Bunting, P.; Hardy, A.; Bell, G. Using Continuous Change Detection and Classification of Landsat Data to Investigate Long-Term Mangrove Dynamics in the Sundarbans Region. Remote Sens. 2019, 11, 2833. [CrossRef] 
24. Tian, Y.; Luo, L.; Mao, D.; Wang, Z.; Li, L.; Liang, J. Using Landsat images to quantify different human threats to the Shuangtai Estuary Ramsar site, China. Ocean Coast. Manag. 2017, 135, 56-64. [CrossRef]

25. Ma, C.; Ye, S.; Lin, T.; Ding, X.; Yuan, H.; Guo, Z. Source apportionment of polycyclic aromatic hydrocarbons in soils of wetlands in the Liao River Delta, Northeast China. Mar. Pollut. Bull. 2014, 80, 160-167. [CrossRef] [PubMed]

26. Gao, X.; Zhang, Y.; Ding, S.; Zhao, R.; Meng, W. Response of fish communities to environmental changes in an agriculturally dominated watershed (Liao River Basin) in northeastern China. Ecol. Eng. 2015, 76, 130-141. [CrossRef]

27. Hansen, M.C.; Loveland, T.R. A review of large area monitoring of land cover change using Landsat data. Remote Sens. Environ. 2012, 122, 66-74. [CrossRef]

28. Claverie, M.; Vermote, E.F.; Franch, B.; Masek, J.G. Evaluation of the Landsat-5 TM and Landsat-7 ETM+ surface reflectance products. Remote Sens. Environ. 2015, 169, 390-403. [CrossRef]

29. Zhu, Z.; Gallant, A.L.; Woodcock, C.E.; Pengra, B.; Olofsson, P.; Loveland, T.R.; Jin, S.; Dahal, D.; Yang, L.; Auch, R.F. Optimizing selection of training and auxiliary data for operational land cover classification for the LCMAP initiative. ISPRS J. Photogramm. Remote Sens. 2016, 122, 206-221. [CrossRef]

30. Zhu, Z.; Wang, S.; Woodcock, C.E. Improvement and expansion of the Fmask algorithm: Cloud, cloud shadow, and snow detection for Landsats 4-7, 8, and Sentinel 2 images. Remote Sens. Environ. 2015, 159, 269-277. [CrossRef]

31. Berhane, T.M.; Lane, C.R.; Mengistu, S.G.; Christensen, J.; Golden, H.E.; Qiu, S.; Zhu, Z.; Wu, Q. Land-Cover Changes to Surface-Water Buffers in the Midwestern USA: 25 Years of Landsat Data Analyses (1993-2017). Remote Sens. 2020, $12,754$. [CrossRef]

32. Pontius, R.G.; Millones, M. Death to Kappa: Birth of quantity disagreement and allocation disagreement for accuracy assessment. Int. J. Remote Sens. 2011, 32, 4407-4429. [CrossRef]

33. Foody, G.M. Status of land cover classification accuracy assessment. Remote Sens. Environ. 2002, 80, 185-201. [CrossRef]

34. Wang, Y.; Ji, Y.; Sun, Z.; Li, J.; Zhang, M.; Wu, G. Analysis of Suaeda heteroptera cover change and its hydrology driving factors in the Liao River Estuary wetlands, China. IOP Conf. Ser. Earth Environ. Sci. 2020, 467, 12150-12158. [CrossRef]

35. Yang, Y.; Chang, Y.; Hu, Y.; Liu, M.; Li, Y. Application of small remote sensing satellite constellations for environmental hazards in wetland landscape mapping: Taking Liaohe Delta, Liaoning Province of Northeast China as a case. Ying Yong Sheng Tai Xue Bao 2011, 22, 1552-1558.

36. Lu, W.; Xiao, J.; Lei., W.; Du., J.; Li, Z.; Cong, P.; Hou, W.; Zhang, J.; Chen, L.; Zhang, Y.; et al. Human activities accelerated the degradation of saline seepweed red beaches by amplifying top-down and bottom-up forces. Ecosphere 2018, 9, $2352-2371$. [CrossRef]

37. Liu, X.; Ke, L.; Zhuang, H.; Yang, X.; Song, N.; Wang, S. Analysis of Coupling Co-Ordination between Intensive Sea Use and the Marine Economy in the Liaoning Coastal Economic Belt of China. Complexity 2020, 2020, 1-13. [CrossRef]

38. Nan, S. Liao river basin of Liaoning tourism development discussed. Territ. Nat. Resour. Study 2015, 25, 71-73.

39. Oleśniewicz, P.; Pytel, S.; Markiewicz-Patkowska, J.; Szromek, A.R.; Jandová, S. A Model of the Sustainable Management of the Natural Environment in National Parks-A Case Study of National Parks in Poland. Sustainability 2020, 12, 2704. [CrossRef]

40. Liu, M.; Liu, S.; Ning, Y.; Zhu, Y.; Valbuena, R.; Guo, R.; Li, Y.; Tang, W.; Mo, D.; Rosa, I.M.D.; et al. Co-Evolution of Emerging Multi-Cities: Rates, Patterns and Driving Policies Revealed by Continuous Change Detection and Classification of Landsat Data. Remote Sens. 2020, 12, 2905. [CrossRef]

41. Zhu, Z.; Woodcock, C.E.; Holden, C.; Yang, Z. Generating synthetic Landsat images based on all available Landsat data: Predicting Landsat surface reflectance at any given time. Remote Sens. Environ. 2015, 162, 67-83. [CrossRef]

42. Tang, W.; Liu, S.; Kang, P.; Peng, X.; Li, Y.; Guo, R.; Jia, J.; Liu, M.; Zhu, L. Quantifying the lagged effects of climate factors on vegetation growth in 32 major cities of China. Ecol. Indic. 2021, 132, 108290. [CrossRef]

43. Jia, M.; Wang, Z.; Liu, D.; Ren, C.; Tang, X.; Dong, Z. Monitoring Loss and Recovery of Salt Marshes in the Liao River Delta, China. J. Coast. Res. 2015, 300, 371-377. [CrossRef]

44. Osland, M.J.; Spivak, A.C.; Nestlerode, J.A.; Lessmann, J.M.; Almario, A.E.; Heitmuller, P.T.; Russell, M.J.; Krauss, K.W.; Alvarez, F.; Dantin, D.D.; et al. Ecosystem Development After Mangrove Wetland Creation: Plant-Soil Change Across a 20-Year Chronosequence. Ecosystems 2012, 15, 848-866. [CrossRef]

45. VanRees-Siewert, K.L.; Dinsmore, J.J. Infuence of Wetland Age on Bird Use of Restored Wetlands in Iowa. Wetlands 1996, 16, 577-582. [CrossRef]

46. Anish, D.; Kanwaljit, K. Age and growth patterns in Channa marulius from Harike Wetland (A Ramsar site), Punjab, India. J. Environ. Biol. 2006, 27, 377-380.

47. Wolf, K.L.; Ahn, C.; Noe, G.B. Development of Soil Properties and Nitrogen Cycling in Created Wetlands. Wetlands 2011, 31, 699-712. [CrossRef]

48. Ahn, C.; Jones, S. Assessing Organic Matter and Organic Carbon Contents in Soils of Created Mitigation Wetlands in Virginia. Environ. Eng. Res. 2013, 18, 151-156. [CrossRef] 